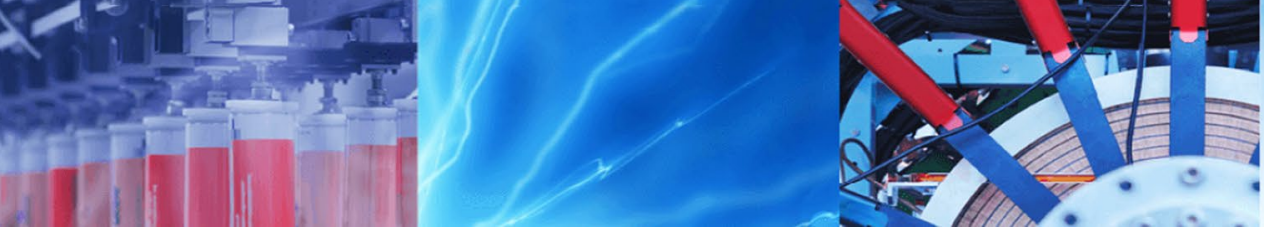

Research Article

\title{
Determination of anthraquinone in tea by stable isotope dilution assay-gas chromatography-tandem mass spectrometry
}

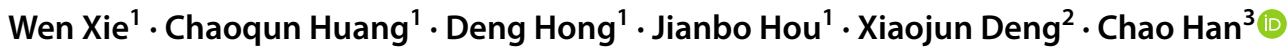

Received: 7 March 2020 / Accepted: 15 May 2020 / Published online: 21 May 2020

(c) Springer Nature Switzerland AG 2020

\begin{abstract}
The aim of this study was to develop an analytical method for the accurate determination of the anthraquinone residue in tea samples (Pu'er tea, oolong tea, green tea, and black tea) by stable isotope dilution assay-gas chromatographytandem mass spectrometry (SIDA-GC-MS/MS). Samples were purified by solid-phase extraction after extraction with $n$-hexane:acetone $(1: 1, v / v)$. The anthraquinone residue was then detected by selected reaction monitoring (SRM) in electron ionization mode. Anthraquinone-d8 was added in the tea sample extraction process to eliminate the matrix effect. The average recoveries were in the range of $84.2-98.1 \%$ at different spiked levels $\left(0.02,0.04\right.$ and $\left.0.08 \mathrm{mg} \mathrm{kg}^{-1}\right)$, and the relative standard deviations were below 9.7\%. The limits of quantification, calculated as 10 times the standard deviation, was $0.02 \mathrm{mg} \mathrm{kg}^{-1}$. The developed method is simple, rapid, and accurate to quantitate the concentration of anthraquinone residues in tea samples.
\end{abstract}

Keywords Anthraquinone residue $\cdot$ Tea $\cdot$ Stable isotope dilution assay $\cdot$ GC-MS/MS

\section{Introduction}

Anthraquinone $(A Q)$ is a widely used chemical product, also known as 9,10-anthraquinone. $A Q$ is often used in the paper pulping and dye industries. As the parent of anthraquinone dye, $A Q$ is used in synthetic disperse dyes, acidic dyes and reactive dyes. As an additive in the papermaking process, $A Q$ can accelerate the delignification rate and increase the yield of pulp [1-4]. The basic parent nucleus of anthraquinones is $A Q$, and natural anthraquinones are mainly hydroxyl anthraquinone derivatives. Anthraquinones are an important secondary metabolite and are the largest group of natural quinones; they can be obtained from many plant species $[5,6]$. Anthraquinones found in rhubarb have a variety of biological and pharmacological properties, such as antibacterial, antiviral, antifungal, antioxidant, anti-atherosclerotic and anticancer activities [7, 8]. Radix Polygonum multiflorum is one of the most popular traditional Chinese medicines, and the main pharmacological functions include tonifying the blood, liver and kidney and strengthening bones and muscles. The glycosides of anthraquinones and other phenolic compounds are considered the main active constituents of radix Polygonum multiflorum [9].

Tea is known to have health benefits, such as antioxidant, anti-inflammatory, and anticancer activities, because it contains large amounts of caffeine, polyphenols, and aromatic substances. Tea is one of the most traditional and popular drinks in China and other foreign countries. China has the largest tea plantation area in the world $[10,11]$.

Pesticides are often used to control pests and protect plant products. Similarly, to protect tea leaves from fungi, weeds or insects, pesticides include AQ must be used throughout the growing process. In addition to $A Q$ as a

Chao Han, chaohan96@hotmail.com |'Zhejiang Academy of Science and Technology for Inspection and Quarantine, Hangzhou 310016, China. ${ }^{2}$ Technical Center for Animal, Plant and Food Inspection and Quarantine of Shanghai Customs, Shanghai 200135, China. ${ }^{3}$ College of Biology and Environmental Engineering, Zhejiang Shuren University, Hangzhou 310015, China. 
pesticide, $A Q$ in tea may be derived from $A Q$ migration in tea packaging. People can indirectly ingest pesticide residues from tea and acquire acute and delayed diseases.

Although AQ is considered a low toxic pesticide, the European Food Safety Authority (EFSA), stated in a reassessment that $A Q$ may have a cancer risk, and the first notification of AQ in tea was issued by the EFSA in 2012 [12]. Currently, AQ has not been registered for agricultural production in the EU or other countries. $A Q$ has also not been registered in Chinese tea and other crops. The EU has set a maximum residue limit (MRL) of $0.02 \mathrm{mg} \mathrm{kg}^{-1}$ for the $A Q$ residue in tea samples to address this issue and the related health problems [13].

Quantitative and qualitative analyses of tea pesticide residues is difficult because there are too many unwanted extracts, such as pigments, sugars, alkaloids and polyphenols. To obtain better analysis results, the coextraction must be reduced during the extraction of tea pesticide residues. Among many techniques, solid-phase extraction (SPE) is considered one of the most effective techniques for coextraction due to its convenience, robustness, and rapidity. Therefore, SPE was used here for the analysis of tea samples $[14,15]$.

Many analytical methods have been reported for the determination of anthraquinones in various samples, such as Rubia tinctorum L., Geosmithia lavendula, Hedyotis diffusa, rat plasma, rhubarb, grape, drinking water and tea, and these methods are LC-UV, CE-DAD, LC-MS, LC-MS/ MS, GC-MS and GC-MS/MS [16-22]. The anthraquinones in the literature and the $A Q$ residue in tea here are two different kinds of compounds. The spectral information of LC-UV and CE-DAD cannot accurately characterize the target object in complex food matrix. One precursor ion of LC-MS and GC-MS was monitored, which cannot meet the criteria of the EU Commission for quantitative mass spectrometric detection requiring a minimum of three identification points for analyte identification [23]. It is easy to cause false positive sample misjudgment. Gas chromatography - tandem mass spectrometry (GC-MS/MS) with multiple reaction monitoring (MRM) mode has been proven to be a powerful and widely used analytical technique for trace pesticides in all kinds of sample because of its high selectivity, precision, sensitivity and confirmation $[24,25]$. Matrix effects have been generally recognized as an important and serious error source in the quantitative analysis of trace-level compounds in food samples by using the GC-MS method [26]. The stable isotope dilution assay (SIDA) is a good way to solve the matrix effect [27]. Anthraquinone- $d_{8}$ was added in the tea sample extraction process to eliminate the matrix effect.

Thus, a method combining SIDA-GC-MS/MS and SPE was established to determine the concentration of the $A Q$ residue in tea leaves in our laboratory. This method is a fast, simple and accurate method to confirm the concentration of the $A Q$ residue in tea samples.

\section{Materials and methods}

\subsection{Reagents and standards}

Certified standards of AQ (CAS No. 84-65-1, 99.0\% purity) and AQ- $d_{8}$ (CAS No. 10439-39-1, 99.0\% purity) were purchased from Dr. Ehrenstorfer GmbH (Augsburg, Germany). Figure 1 is the chemical structurals formula of the standard product. Acetone, $n$-hexane and ethyl ether were obtained from J.T. Baker (Scharlau, Spain). Anhydrous sodium sulfate (Sinopharm Chemical Reagent Co., Ltd, Shanghai, China) was burned for $4 \mathrm{~h}$ in a muffle furnace at $650{ }^{\circ} \mathrm{C}$ before use. Florisil (75-150 $\mu \mathrm{m}$, Sinopharm Chemical Reagent Co., Ltd, Shanghai, China) was first heated for $4 \mathrm{~h}$ in a muffle furnace at $650^{\circ} \mathrm{C}$ then cooled to room temperature, and $2 \%$ water was added before use. Ultrapure water was obtained from a Milli-Q water purification system from Millipore (Bedford, MA, USA).

\subsection{Preparation of standard solutions}

The concentrations of $A Q$ and $A Q-d_{8}$ individual standard stock solutions prepared in acetone were $400 \mathrm{\mu g} \mathrm{mL}^{-1}$, and
Fig. 1 Chemical structure of Anthraquinone $\mathbf{a}$ and Anthraquinone- $d_{8} \mathbf{b}$

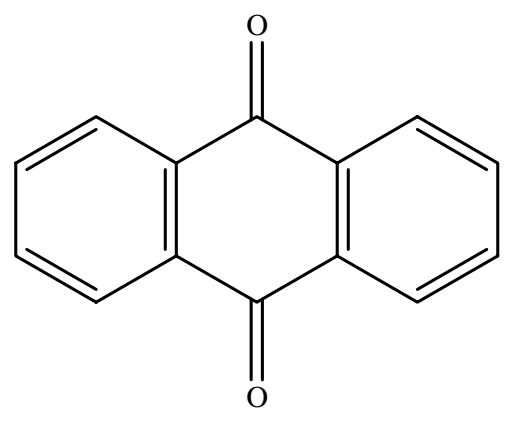

(A)<smiles>[2H]c1c([2H])c([2H])c2c(c1[2H])C(=O)c1c([2H])c([2H])c([2H])c([2H])c1C2=O</smiles>

(B) 
these solutions were stored at $0-4{ }^{\circ} \mathrm{C}$ away from light. Acetone was used in the dilution process. The standard curve had five concentration points as follows: $0.01,0.02,0.04$, 0.08 and $0.2 \mathrm{mg} \mathrm{L}^{-1}$. As the internal standard used in this work, the final concentration of AQ- $\mathrm{d}_{8}$ was $0.05 \mathrm{mg} \mathrm{L}^{-1}$.

\subsection{Sample extraction}

Representative tea samples of approximately $250 \mathrm{~g}$ were milled to powder (ca. 20 mesh) by a disintegrator (Philips HR 2168, Huizhou, China). After accurately weighing $2.0 \mathrm{~g}$ tea powder sample into a $50-\mathrm{mL}$ polypropylene centrifuge tube, the first step was to add the $0.5 \mathrm{~mL} \mathrm{AQ}-\mathrm{d}_{8}$ internal standard solution $\left(0.2 \mathrm{mg} \mathrm{L}^{-1}\right)$. Then, $20 \mathrm{~mL}$ $n$-hexane:acetone $(1: 1, v / v)$ was added as the extraction solvent. The mixture was swirled for 1 min before adding $2.0 \mathrm{~g}$ sodium chloride, swirled for $1 \mathrm{~min}$, and centrifuged for $5 \mathrm{~min}$ at $4000 \mathrm{r} \mathrm{min}^{-1}$. Then the supernatant was transferred into a flask. The extraction process was repeated twice and the extracts were combined. The combined extract was concentrated to nearly dryness in a $45{ }^{\circ} \mathrm{C}$ water bath. The concentrate was dissolved with $3.0 \mathrm{~mL}$ of $\mathrm{n}$-hexane and swirled for $1 \mathrm{~min}$. This solution was used for the subsequent purification.

\subsection{Purification}

A florisil solid phase extraction (SPE) cartridge (200 $\mathrm{mm} \times 15 \mathrm{~mm}$ id) was homemade in our laboratory. This cartridge was packed from bottom to top with glass wool $(5 \mathrm{~mm})$, anhydrous sodium sulfate $(10 \mathrm{~mm})$, florisil ( $10 \mathrm{~g}, 2 \%$ deactivated) and anhydrous sodium sulfate $(10 \mathrm{~mm})$. The column was conditioned with $20 \mathrm{~mL}$ of $n$-hexane. Three milliliters of the $n$-hexane-dissolved solution was poured onto the conditioned column and eluted by gravity. The column was then eluted with $50 \mathrm{~mL}$ of n-hexane:diethyl ether $(8: 2, v / v)$ into a flask, and the eluate was evaporated to nearly dryness in a $45^{\circ} \mathrm{C}$ water bath. The concentrate was dissolved with $2.0 \mathrm{~mL}$ of acetone and swirled for $1 \mathrm{~min}$. After filtering through a $0.22 \mu \mathrm{m}$ nylon membrane, the concentrate was transferred to an auto sampler vial for GC-MS/MS analysis.

\subsection{GC-MS/MS analysis}

GC-MS/MS analysis was carried out using a Thermo Fisher Trace 1300 GC coupled with a Thermo Fisher TSQ 8000 triple quadrupole mass spectrometer (Thermo Fisher Scientific, Waltham, MA, USA). Analytes were separated on a HP-5 MS $30 \mathrm{~m} \times 0.25 \mathrm{~mm} \times 0.25 \mu \mathrm{m}$ capillary column. The carrier gas was helium ( $99.9999 \%$ purity) at a flow rate of $1.0 \mathrm{~mL} \mathrm{~min}{ }^{-1}$. The oven temperature program was initially $100^{\circ} \mathrm{C}$ (held for $1 \mathrm{~min}$ ), and the temperature was increased to $300^{\circ} \mathrm{C}$ at $20^{\circ} \mathrm{C} \mathrm{min}^{-1}$. The injector temperature was set to $300^{\circ} \mathrm{C}$. The injection mode was splitless, and the injection volume was $1.0 \mu \mathrm{L}$.

The MS/MS was operated in electron ionization (EI) mode. The temperature of the ion source and transfer line were set at $280^{\circ} \mathrm{C}$ and $300^{\circ} \mathrm{C}$, respectively. Selected reaction monitoring (SRM) mode was used for quantitative analysis; each compound had one parent ion and two product ions. Table 1 shows the analytical conditions for GC-MS/MS, including the retention times, parent ion, product ion and their optimal collision energies.

\section{Results and discussion}

\subsection{Optimization of GC-MS/MS Conditions}

To accurately identify trace $A Q$ residues in tea samples, MS/MS conditions were first optimized to determine the parent ions of the $A Q$ and $A Q-d_{8}$ targets. When the parent ions were selected, the optimal product ion was found by examining the different values of the collision energies, and the product ion with the highest abundance was used as the quantitative ion. This is in strict compliance with EU regulations [23]. Table 1 lists the optimized mass spectrum parameters.

The separation efficiency of different chromatographic columns was investigated, and an HP-5 MS column showed the best performance. Figure 2 is GC-MS/ MS SRM chromatograms of a real Pu'er tea (A), Oolong tea (B), Green tea (C), Black tea (D) sample (STD, standard), (BK, sample), (SP, spike). The background of the SRM chromatogram was very clean, indicating that there were no
Table 1 Analytical conditions for GC-MS/MS

\begin{tabular}{lllll}
\hline Compounds & Retention time $(\mathrm{min})$ & Parent ion $(\mathrm{m} / \mathrm{z})$ & Product ion $(\mathrm{m} / \mathrm{z})$ & $\begin{array}{l}\text { Collision } \\
\text { energy }(\mathrm{eV})\end{array}$ \\
\hline Anthraquinone & \multirow{2}{*}{8.5} & 208.0 & $180.0^{*}$ & 10 \\
& & 208.0 & 152.0 & 30 \\
Anthraquinone- $\mathrm{d}_{8}$ & & 216.0 & $188.0^{*}$ & 10 \\
& & 216.0 & 160.0 & 30 \\
\hline
\end{tabular}

*The MS/MS transition was used for quantitation 

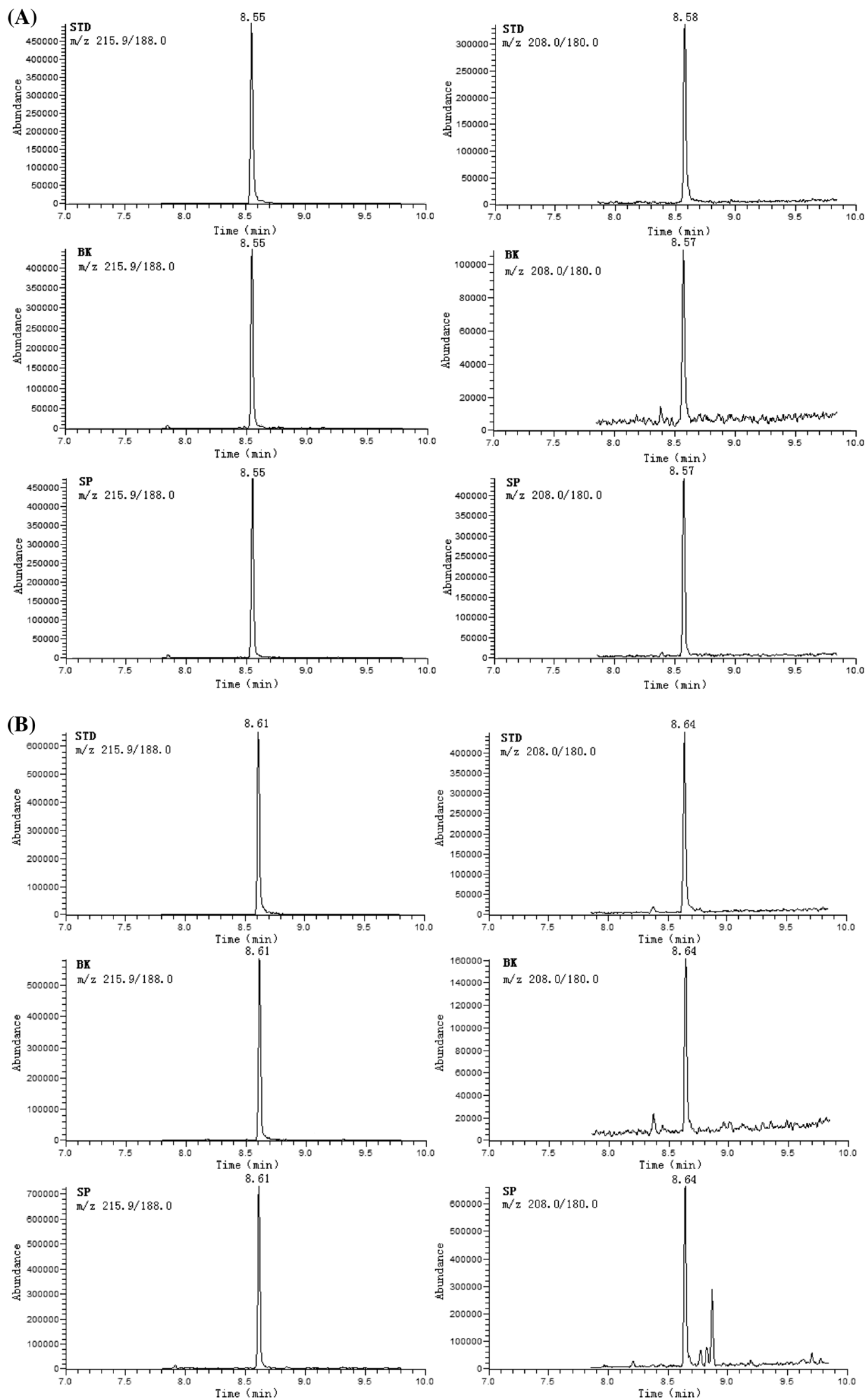

Fig. 2 GC-MS/MS SRM chromatograms of a real Pu'er tea a, Oolong tea b, Green tea c, Black tea d sample (STD, standard), (BK, sample), (SP, spiked with $0.02 \mathrm{mg} \mathrm{kg}^{-1}$ )

\section{SN Applied Sciences}


(C)
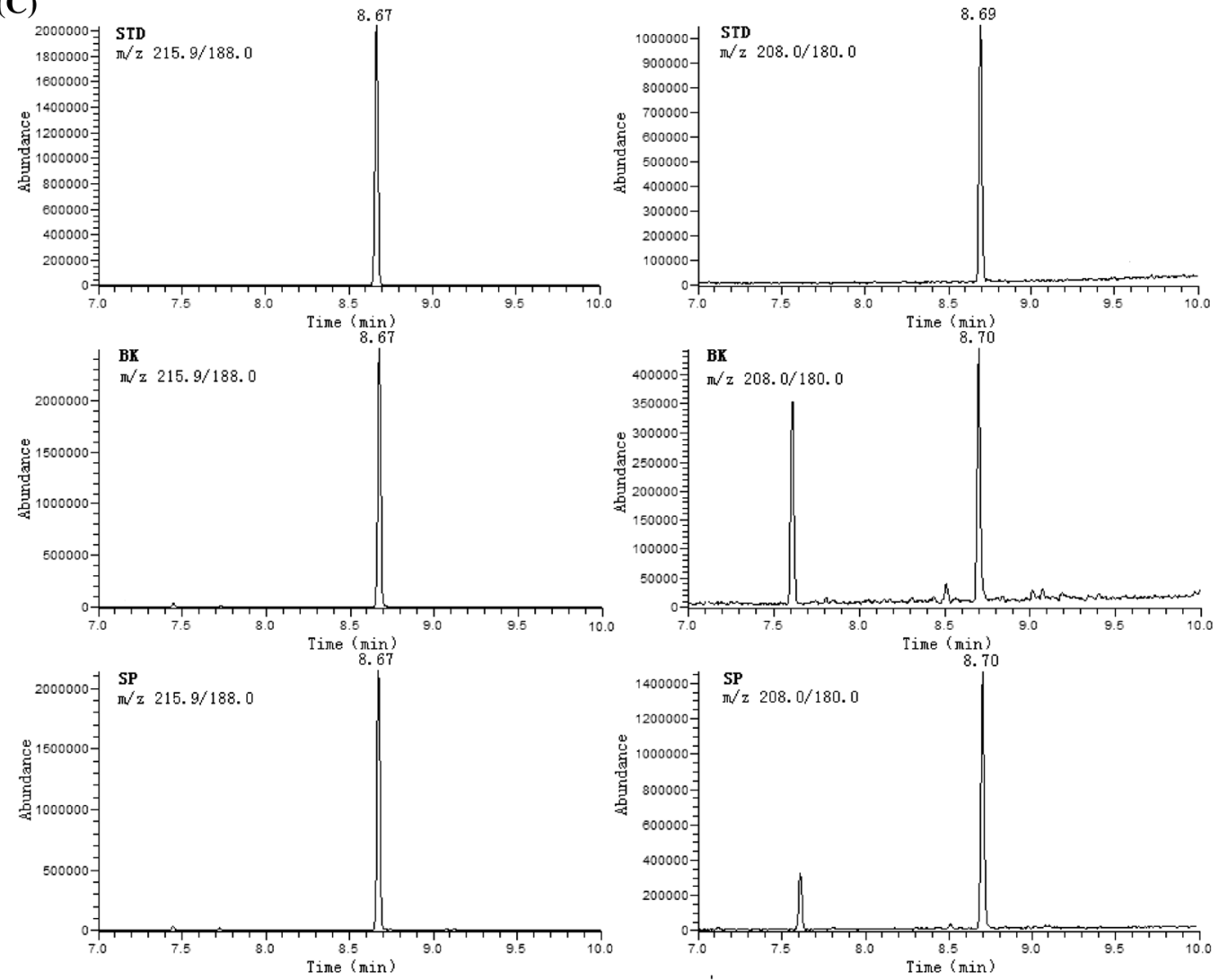

(D)
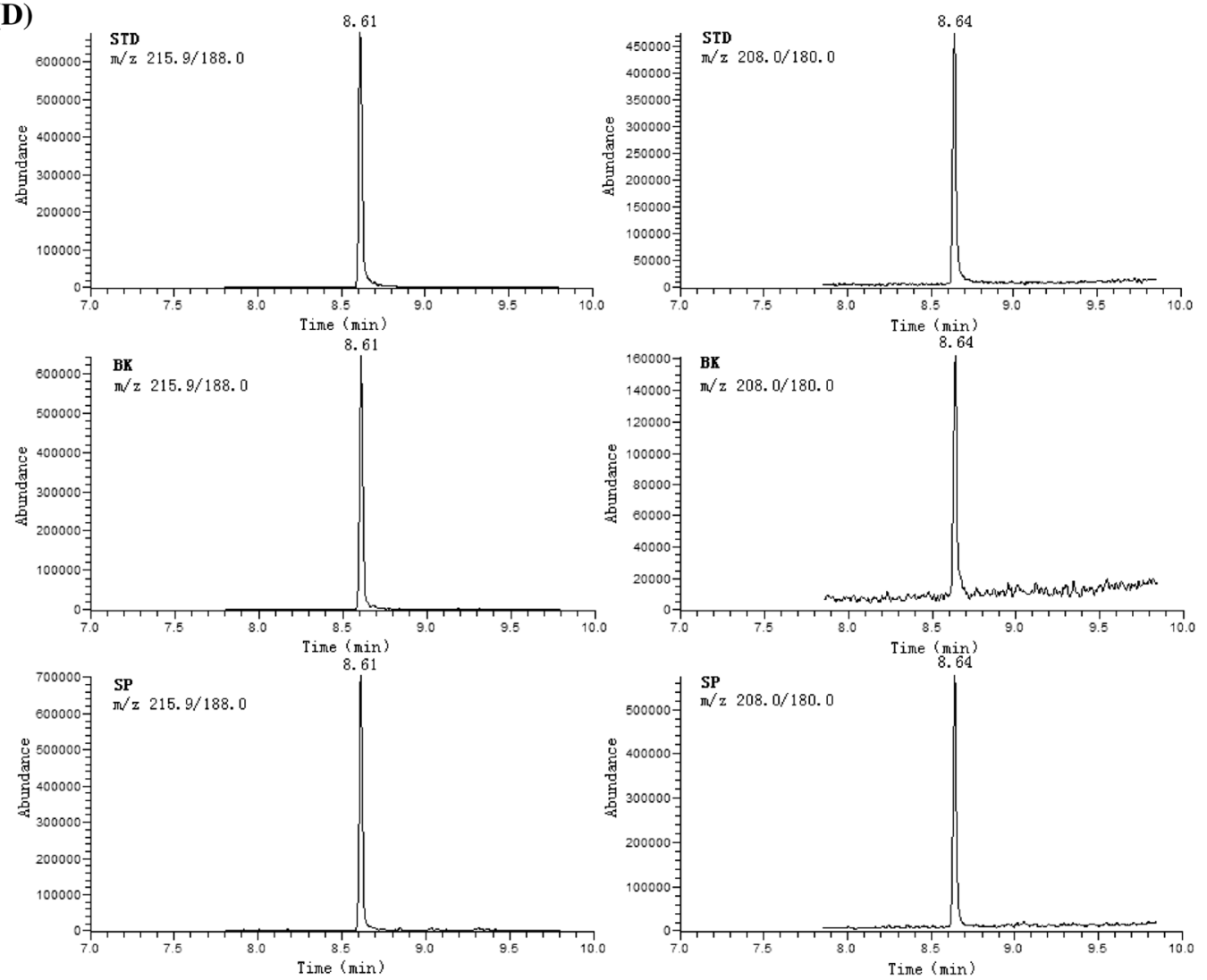

Fig. 2 (continued) 
impurity interferences during the SRM analysis. Figure 3 shows the GC-MS/MS product scan spectra of the investigated $A Q$ and $A Q-d_{8}$ compounds.

\subsection{Optimization of extraction and SPE clean-up method}

The extraction process parameters were optimized to obtain the optimal extraction efficiency. The same positive sample of green tea was extracted with several different organic solvents, such as $n$-hexane:acetone $(1: 1, v / v)$, acetonitrile, ethyl acetate and acetone. The acetonitrile extract was the lightest in color, and the acetone extract was the darkest in color. After enrichment, the thickening acetone extract was not easily further purified because of the strong polarity of acetone. The $A Q$ residue extracted from green tea-positive samples with different extraction organic solvents was $0.026 \mathrm{mg} \mathrm{kg}^{-1}$ (acetonitrile), $0.059 \mathrm{mg} \mathrm{kg}^{-1}$ (acetone), $0.07 \mathrm{mg} \mathrm{kg}^{-1}$ (n-hexane:acetone $(1: 1, \mathrm{v} / \mathrm{v}))$, and $0.042 \mathrm{mg} \mathrm{kg}^{-1}$ (ethyl acetate). For the AQ compound in the tea sample, n-hexane:acetone $(1: 1$, $\mathrm{v} / \mathrm{v}$ ) was the most suitable extraction solvent. Therefore, n-hexane:acetone $(1: 1, v / v)$ was used for extraction in subsequent experiments for different extraction times. The results showed that no AQ was observed after two extraction.

The pesticide residue test results were different depending on whether the dry plant samples were rehydrated. The same green tea-positive sample was compared; one sample was soaked in $8 \mathrm{~mL}$ for half an hour, and the other sample did not have added water. Subsequent extraction and purification steps were the
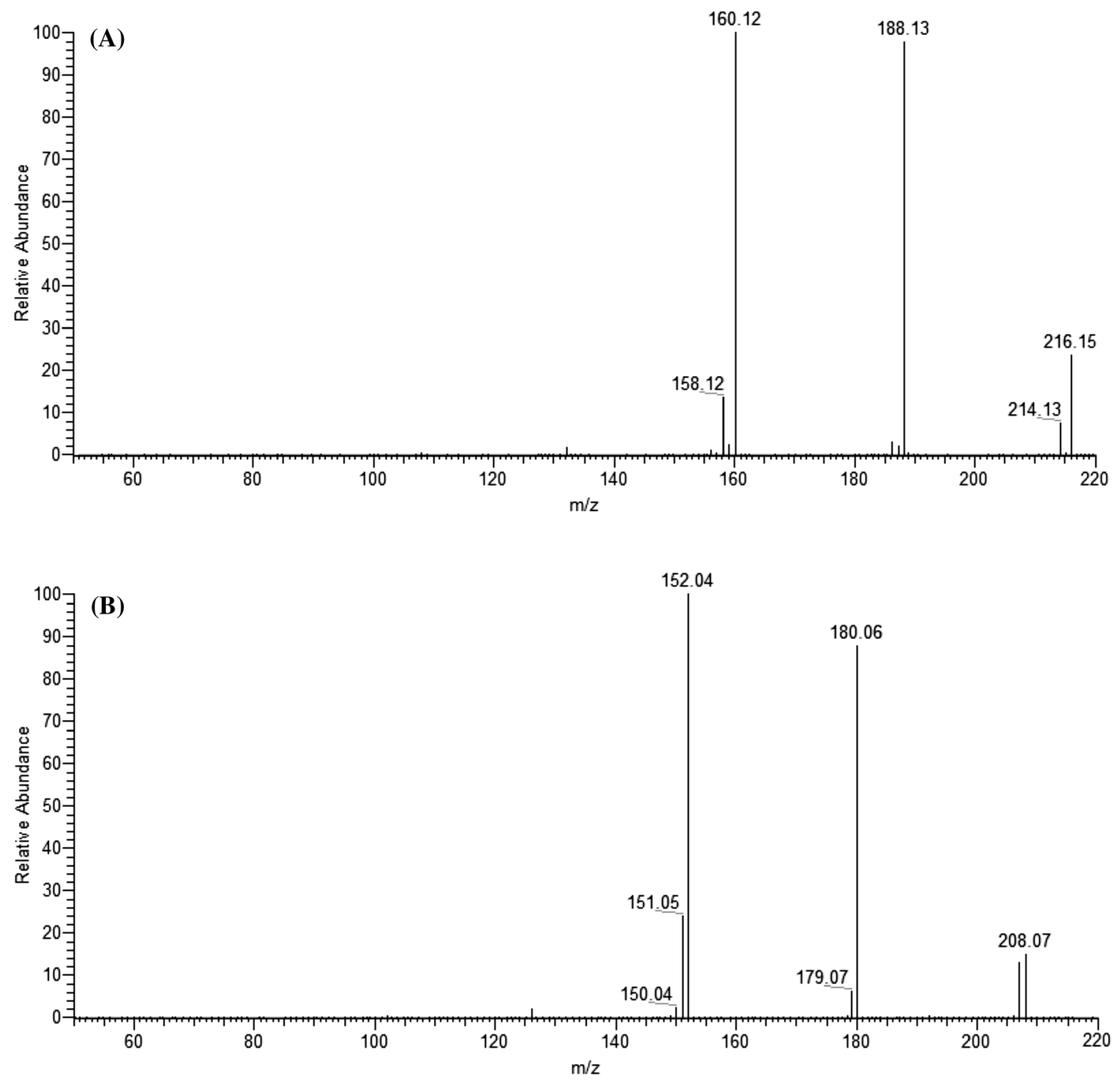

Fig. 3 GC-MS/MS product scan spectrum of Anthraquinone- $d_{8}$ a and Anthraquinone $\mathbf{b}$ 
same. The $A Q$ residue extracted from the green teapositive sample was $0.066 \mathrm{mg} \mathrm{kg}^{-1}$ (added water) and $0.070 \mathrm{mg} \mathrm{kg}^{-1}$ (no added water), and there were no significant differences in the test results. Therefore, further experiments used the method of direct extraction by $\mathrm{n}$-hexane:acetone $(1: 1, \mathrm{v} / \mathrm{v})$ without soaking in water.

The main interfering compounds that have been coextracted from tea samples are sugars, pigments, polyphenols and alkaloids [28]. Therefore, these coextracted compounds pose a great challenge and contaminate the instrument for GC-MS/MS if the necessary purification means are not adopted and direct sampling is used for analysis, despite GC-MS/MS having high selectivity. On the other hand, concentration levels of the targets that are too low are a challenge for accurate qualitative and quantitative analyses by these instruments. Therefore, purification and enrichment methods are essential for pesticide residue analysis. Three different solid-phase extraction (SPE) methods were used here for both clean-up and enrichment. Florisil SPE column (10 g, homemade), florisil SPE column (Agela Technologies, $5 \mathrm{~g}, 25 \mathrm{~mL}$, China), and florisil SPE column (Supelco, $1 \mathrm{~g}, 6 \mathrm{~mL}$, USA) were compared. The florisil SPE column (10 $\mathrm{g}$, homemade) showed the best result for the green tea-positive samples. The AQ residue extracted from green tea-positive samples with different SPE columns was $0.069 \mathrm{mg} \mathrm{kg}^{-1}$ (homemade), $0.056 \mathrm{mg} \mathrm{kg}^{-1}$ (Agela Technologies) and $0.052 \mathrm{mg} \mathrm{kg}^{-1}$ (Supelco). Thus, the florisil Florisil SPE column ( $10 \mathrm{~g}$, homemade) was used in the following experiments.

\subsection{Linearity and quantification limits}

When using LC-MS/MS or GC-MS/MS to quantitatively analyze various compounds in food samples, matrix effects are considered to be the most important factor affecting the accuracy of the results. The best way to solve the matrix effect is to apply stable isotope dilution assay (SIDA) [29]. To overcome the matrix effects, Anthraquinone-d8 was added in the tea sample extraction process to eliminate the matrix effect and satisfactory results were obtained. A series of isotope-labeled internal standard calibrations ranging from 0.01 to $0.2 \mathrm{mg} \mathrm{L}^{-1}$ were used, and the final isotope-labeled internal standard $\left(A Q-d_{8}\right)$ concentration was $0.05 \mathrm{mg} \mathrm{L}^{-1}$. Calibration curve with $1 / \mathrm{x}$ weighting was plotted for the analyte. Quantification was performed based on calibration plots using the peak area of the most intense transition of the analyte.

At the same time, the linearity was good, and the correlation coefficient was 0.9995 . The limits of quantification, calculated as 10 times the standard deviation, was $0.02 \mathrm{mg} \mathrm{kg}^{-1}$ for all samples.

\subsection{Precision and accuracy}

After extraction and purification of 10 different tea samples, there were no interfering substances around the retention time of the target analytes, which is indicative of the specificity of this method.

The accuracy of the method was measured by the sample spike recovery. The average recoveries at three spiking levels (low, medium and high) were 84.2-98.1\% (Table 2). Relative standard deviation (RSD) were less than $9.7 \%$, which is indicative of the good recovery and precision of the method.

\subsection{Application to real samples}

This method was applied to analyze 100 different types of tea samples on the market ( 25 portions of Pu'er tea, oolong tea, green tea, and black tea). 100 different types of tea samples from 8 provinces (Zhejiang, Jiangsu, Hunan, Hubei, Fujian, Yunnan, Sichuan and Guangxi Province) of China were bought at random in different supermarket and tea shop in Hanzhou City. These tea samples are for sale. They were packaged with aluminum foil. 100 different types of tea samples are extracted, purified and determined by GC-MS/MS as described in this method. AQ was detected in 8 samples in the four tea types and was not detected in the other samples at less than $0.02 \mathrm{mg} \mathrm{kg}^{-1}$. The frequency of $A Q$ presence in green tea was the highest, with values of $0.03,0.03,0.04$, and $0.05 \mathrm{mg} \mathrm{kg}^{-1}$. The $A Q$ contents in oolong [2], black [1], and Pu'er tea [1] teas were 0.03 and 0.04; 0.04; and $0.03 \mathrm{mg} \mathrm{kg}^{-1}$, respectively.

Table 2 Mean Recoveries and Repeatability of the Developed Method at Three Concentration Levels with LOQs $(n=6)$

\begin{tabular}{lllll}
\hline Tea & Spiking level & Recovery (\%) & RSD (\%) & LOQ $\mathrm{mg} \mathrm{kg}^{-1}$ \\
\hline Green tea & 0.02 & 86.7 & 8.4 & 0.02 \\
& 0.04 & 92.5 & 6.3 & \\
Black tea & 0.08 & 94.6 & 5.2 & \\
& 0.02 & 85.1 & 9.7 & \\
& 0.04 & 93.1 & 7.2 & \\
Pu'er tea & 0.08 & 95.2 & 5.1 & \\
& 0.02 & 84.2 & 5.5 & \\
& 0.04 & 92.5 & 4.4 & \\
Oolong tea & 0.08 & 98.1 & 1.7 & \\
& 0.02 & 85.0 & 8.2 & \\
& 0.04 & 93.4 & 6.1 & \\
& 0.08 & 95.3 & 3.4 & \\
\hline
\end{tabular}




\section{Conclusions}

In this study, the method described combines solid-phase extraction with stable isotope dilution assay-gas chromatraphy-tandem mass spectrometry (SIDA-GC-MS/MS) for the determination of the concentration of the $A Q$ residue in tea samples (Pu'er tea, oolong tea, green tea, and black tea). Good recoveries (84.2-98.1\%) and precision (RSD values below 9.7\%) were obtained. The results indicated that the method presented in this study is a fast, simple and accurate method to confirm the concentration of the $A Q$ residue in tea samples.

Acknowledgments Financial support from the Science Technology Department of Zhejiang Province (2015C12001), the Science Technology Department of Wenzhou City (2018ZG013) and the Science Technology Department of Shanghai (15395810100) is gratefully acknowledged.

\section{Compliance with ethical standards}

Conflict of interest All the authors have no potential conflicts of interest.

Ethical approval This article does not contain any studies with animals or human participants performed by any of the authors.

\section{References}

1. Gonzalo A, Bimbela F, Sanchez JL, Labidi L, Marín F, Arauzo J (2017) Evaluation of different agricultural residues as raw materials for pulp and paper production using a semichemical process. J Clean Prod 156:184-193

2. Li YX, Tan TF, Wang SR, Xiao Y, Li XG (2017) Highly solvatochromic fluorescence of anthraquinone dyes based on triphenylamines. Dyes Pigm 144:262-270

3. Mauldin RE, Primus TM, Volz SA, Kimball BA, Johnston JJ, Commings JJ, York DL (2002) Determination of anthraquinone in technical material, formulations, and lettuce by high performance liquid chromatography. J Agric Food Chem 50:3632-3636

4. Rybczyńska-Tkaczyk K, Święciło A, Szychowski KA, KorniłłowiczKowalska T (2018) Comparative study of eco- and cytotoxicity during biotransformation of anthraquinone dye Alizarin Blue Black B in optimized cultures of microscopic fungi. Ecotox Environ Safe 147:776-787

5. Aichner D, Ganzera M (2015) Analysis of anthraquinones in rhubarb (Rheum palmatum and Rheum officinale) by supercritical fluid chromatography. Talanta 144:1239-1244

6. Duval J, Pecher V, Poujol M, Lesellier E (2016) Research advances for the extraction, analysis and uses of anthraquinones: a review. Ind Crops Prod 94:812-833

7. Wang J, Zhao H, Kong W, Jin C, Zhao Y, Qu Y, Xiao X (2010) Microcalorimetric assay on the antimicrobial property of five hydroxyanthraquinone derivativesin rhubarb (Rheum palmatum L.) to Bifidobacterium adolescentis. Phytomedicine 17:684-689

8. Wei SY, Yao WX, Ji WY, Wei JQ, Peng SQ (2013) Qualitative and quantitative analysis of anthraquinones in rhubarbs by high performance liquid chromatography with diode array detector and mass spectrometry. Food Chem 141:1710-1715

9. Zuo YG, Wang CJ, Lin YJ, Guo JW, Deng YW (2008) Simultaneous determination of anthraquinones in radix Polygoni multiflori by capillary gas chromatography coupled with flame ionization and mass spectrometric detection. J Chromatogr A 1200:43-48

10. Wang FQ, Li SH, Feng H, Yang YJ, Xiao B, Chen DW (2019) An enhanced sensitivity and cleanup strategy for the nontargeted screening and targeted determination of pesticides in tea using modified dispersive solid-phase extraction and cold-induced acetonitrile aqueous two-phase systems coupled with liquid chromatography-high resolution mass spectrometry. Food Chem 275:530-538

11. Zhu P, Miao H, Du J, Zou JH, Zhang GW, Zhao YF, Wu YN (2014) Organochlorine pesticides and pyrethroids in chinese tea by screening and confirmatory detection using GC-NCl-MS and GC-MS/MS. J Agric Food Chem 62:7092-7100

12. https://webgate.ec.europa.eu/rasff-window/portal/?event $=$ SearchForm\&cleanSearch $=1$

13. Commission Regulation (EU) No 1146/2014 of 23 October 2014, Official Journal of the European Union, 29.10.2014, L 308/3

14. Bai YL, Cai BD, Luo XT, Ye TT, Feng YQ (2018) Simultaneous determination of abscisic acid and its catabolites by hydrophilic solidphase extraction combined with ultra high performance liquid chromatography-tandem mass spectrometry. J Agric Food Chem 66:10906-10912

15. Zheng Z, Zhao XE, Zhu S, Dang J, Qiao X, Qiu Z, Tao Y (2018) Simultaneous determination of oleanolic acid and ursolic acid by in vivo microdialysis via UHPLC-MS/MS using magnetic dispersive solid phase extraction coupling with microwaveassisted derivatization and its application to a pharmacokinetic study of Arctiumlappa L. Root Extract in Rats. J Agric Food Chem 66:3975-3982

16. Derksen GC, Niederlände HA, van Bee TA (2002) A nalysis of anthraquinones in Rubia tinctorum L. by liquid chromatography coupled with diode-array UV and mass spectrometric detection. J Chromatogr A 978:119-127

17. Wang N, Su M, Liang SX, Sun HW (2016) Investigation of six bioactive anthraquinones in slimming tea by accelerated solvent extraction and high performance capillary electrophoresis with diode-array detection. Food Chem 199:1-7

18. Stodulkova E, Man P, Kolarík M, Flieger M (2010) High-performance liquid chromatography-off line mass spectrometry analysis of anthraquinones produced by Geosmithia lavendula. J Chromatogr A 1217:6296-6302

19. Liu EH, Zhou T, Li GB, Li J, Huang XN, Pan F, Gao N (2012) Characterization and identification of iridoid glucosides, flavonoids and anthraquinones in Hedyotis diffusa by high-performance liquid chromatography/electrospray ionization tandemmass spectrometry. J Sep Sci 35:263-272

20. Wang JB, Qin Y, Kong WJ, Wang ZW, Zeng LN, Fang F, Jin C, Zhao $Y L$, Xiao XH (2011) Identification of the antidiarrhoeal components in official rhubarb using liquid chromatography-tandem mass spectrometry. Food Chem 129:1737-1743

21. Zhu H, Liu X, Zhu TT, Wang XL, Qin KM, Pei K, Cai BC (2017) UHPLMS/MS method for the simultaneous quantitation of five anthraquinones and gallic acid in rat plasma after oral administration of prepared rhubarb decoction and its application to a pharmacokinetic study in normal and acute blood stasis rats. J Sep Sci 40:2382-2389

22. Tillner J, Hollard C, Bach C, Rosin C, Munoz JF, Dauchy X (2013) Simultaneous determination of polycyclic aromatic hydrocarbons and their chlorination by-products in drinking water and the coatings of water pipes by automated solid-phase microextraction followed by gas chromatography-mass spectrometry. J Chromatogr A. 1315:36-46 
23. Commission Decision 2002/657/EC of 12 August 2002. Implementing Council Directive 96/23/EC Concerning the Performance of Analytical Methods and the Interpretation of Results, European Union, Brussels, 2002

24. Maestroni B, Abu Alnaser A, Ghanem I, Islam M, Cesio V, Heinzen $\mathrm{H}$, Kelly S (2018) Validation of an analytical method for the determination of pesticide residues in vine leaves by GC-MS/MS. J Agric Food Chem 66:6421-6430

25. Silveira AL, de Oliveira MLG, Rocha DG, Dracz S, Borgati TF, Lana MAG, Augusti R, Faria AF (2018) Multiresidue determination of the anabolic-agent residues steroids, stilbenes, and resorcylic acid lactones in bovine urine by GC-MS/MS with microwaveassisted derivatization. J Agric Food Chem 66:8630-8638

26. Yu S, Xu XM (2012) Study of matrix-induced effects in multiresidue determination of pesticides by online gel permeation chromatography-gas chromatography/mass spectrometry. Rapid Commun Mass Spectrom 26:963-977

27. Hou JB, Xie W, Hong D, Zhang W, Li F, Qian Y, Han C (2019) Simultaneous determination of ten neonicotinoid insecticides and two metabolites in honey and Royal-jelly by solid-phase extraction and liquid chromatography-tandem mass spectrometry. Food Chem 270:204-213

28. Jiang H, Yu F, Qin L, Zhang N, Cao Q, Schwab W, Li DX, Song CK (2019) Dynamic change in amino acids, catechins, alkaloids, and gallic acid in six types of tea processed from the same batch of fresh tea (Camellia sinensis L.) leaves. J Food Compos Anal 77:28-38

29. Shen Y, Hu BZ, Chen XZ, Miao Q, Wang CJ, Zhu ZO, Han C (2014) Determination of four flavorings in infant formula by solidphase extraction and gas chromatography-tandem mass spectrometry. J Agric Food Chem 62:10881-10888

Publisher's Note Springer Nature remains neutral with regard to jurisdictional claims in published maps and institutional affiliations. 